\title{
Que bichos conhecemos? Trabalhando classificação a partir de conhecimentos tradicionais com jovens rurais da EFA Valente Diany kelly Cardoso de Sousa ${ }^{1}$; Alessandra Alexandre freixo ${ }^{2}$ \\ 1. Bolsista PIBIC/CNPq, Licenciatura em Ciências Biológicas, Universidade Estadual de Feira de Santana, e-mail: dianisousa@hotmail.com \\ 2. Orientador, DEDU, Universidade Estadual de Feira de Santana, e-mail: aafreixo@hotmail.com
}

PALAVRAS-CHAVE: Educação do campo, Diversidade e classificação, Etnobiologia.

\section{INTRODUÇÃO}

O presente trabalho relata as atividades de pesquisa realizadas junto a escola Família Agrícola Avani de Lima Cunha, cujo foco esteve voltado para o diálogo de saberes, por meio de oficinas interdisciplinares envolvendo a temática Diversidade Biológica animal. Com o intuito de realizar um levantamento dos conhecimentos etnozoológicos dos estudantes da Escola Família Agrícola de Valente, de modo a conhecer as estratégias de classificação biológica utilizadas por eles, como meio de promover um diálogo entre saberes tradicionais e científicos na escola. E por fim avaliar qual a potencialidade de oficinas de ciências que versam sobre o tema da diversidade e classificação biológica na promoção do diálogo entre saberes.

A escola do campo assim como o campo, possui cultura própria, cultura esta que está associada aos conhecimentos tradicionais, que podem ser definidos como "o saber e o saber fazer, a respeito do mundo natural e sobrenatural, gerados no âmbito da sociedade não urbano/industrial e transmitidos oralmente de geração em geração" (DIEGUES, 2000, p 30). Possuindo assim sua própria interpretação da natureza e de seus fenômenos. O homem têm utilizado diferentes modos de classificação que expressam diferentes formas de entender e explicar o universo e os seres que nele vivem. Esse conhecimento compõe a marca de determinados grupos e não pode ser desconsiderado ou inferiorizado no processo de ensino e aprendizagem de ciências. Portanto ao trabalhar com diversidade biológica, é imprescindível, conforme Baptista (2010), a demarcação e a promoção do diálogo entre o saber tradicional e o científico.

A escola em questão, desenvolve seu projeto a partir do preceito da Pedagogia da Alternância (EFA VALENTE, 2015), e neste contexto educacional, os estudantes tem a oportunidade de um diálogo constante entre conhecimentos oriundos do ambiente familiar e aqueles adquiridos no processo de educação formal, escolarizada, abre-se portanto um campo profícuo de pesquisa e intervenção, tomando os princípios teóricometodológicos da etnobiologia. A etnobiologia enquanto ciência que em essência se ocupa em estudar os diferentes conceitos e conhecimentos produzidos por diferentes grupos sociais sobre questões biológicas (POSEY, 1987), permite a articulação entre diferentes culturas e diferentes modos de conhecer e conceber a natureza, por isso, optou-se por utilizá-la como ponte pela qual se estabeleceria o diálogo de saberes durante a realização dessa pesquisa.

\section{METODOLOGIA}

Essa pesquisa se pauta nos aspectos metodológicos da pesquisa-ação, tal como propõe Tripp (2005), e teve como participantes estudantes do $7^{\circ}$ e $9^{\circ}$ ano do ensino fundamental. Ao longo deste trabalho, foram desenvolvidas estratégias participativas de pertencimento ao lugar envolvendo a comunidade escolar. As oficinas ocorreram em três momentos distintos: No primeiro momento com as turmas, foi apresentada a 
proposta: "Oficina Bichos que Conhecemos", os estudantes foram estimulados a escolher, citar e desenhar um animal, que fizesse parte ou não de seu cotidiano. No segundo encontro os estudantes realizaram classificações intuitivas, com os animais citados na etapa anterior e por fim, no terceiro encontro tendo em mãos o livreto produzido a partir da sistematização da lista de animais, das classificações intuitivas feitas pelos estudantes e a classificação cientifica, abrimos espaço para o diálogo de saberes estimulando os estudantes a perceber se havia semelhanças ou diferenças entre os modos de agrupar os seres. Neste último encontro ocorreu a culminância da oficina, com a socialização das produções dos estudantes para a toda comunidade escolar.

Como principal técnica de análise de dados, utilizou-se da Análise de Conteúdo apresentada por Bardin (2004), para análise das narrativas advindas das transcrições das gravações e dos escritos dos estudantes.

\section{RESULTADOS E/OU DISCUSSÃO}

Os distintos grupos taxonômicos entre os bichos escolhidos pelos estudantes foram citados nas seguintes proporções: $57 \%$ mamíferos; $13 \%$ aves; $11 \%$ répteis; $9 \%$ insetos; $4 \%$ peixes; $2 \%$ crustáceos; $2 \%$ aracnídeos e $2 \%$ anfíbios. A partir das informações obtidas, é possível inferir que mamíferos constituem o grupo mais amplamente conhecido, pois foram os mais citados, $26 \mathrm{em}$ um total de 46. Em segundo lugar se encontram as aves, citados por 6 estudantes.

Os animais mais citados foram aqueles que apresentam uma ampla utilização, seja na alimentação, ou como animais domésticos, aos quais se atribui valor afetivo ou econômico. Tal afirmação se confirma ao analisar as justificativas dadas pelos estudantes para a escolha dos respectivos animais, como por exemplo, a escolha de 13 dos 26 mamíferos citados está diretamente ligada ao fato de o animal ser usado na alimentação, por apresentar valor econômico, afetivo ou cultural.

A onça, por exemplo, se enquadra no conjunto de animais que foram escolhidos por que de alguma forma despertam interesse, curiosidade, chamam atenção por sua agilidade, pelo tamanho, por que são predadores hábeis, ferozes (essas foram palavras usadas pelos alunos para descrever os "bichos" escolhidos), a exemplo:

[Escolhi a onça pintada] porque eu admiro muito ela é um animal muito bonito, muito feroz (justificativa por estudante do $9^{\circ}$ ).

Philippe Descola, antropólogo francês, fala que as manifestações de simpatia pelos animais se dão com base em uma escala de valor que o próprio ser humano confere aos grupos animais, sendo o "ápice ocupado pelas espécies percebidas como as mais próximas do homem em função de seu comportamento, fisiologia, faculdades cognitivas ou da capacidade que lhes é atribuída de sentir emoções" (DESCOLA, 1998, p. 23), ocupando os mamíferos tal posição.

O senso de pertencimento cultural também se evidencia nas falas e desenhos; alguns estudantes justificaram a escolha do animal por este de alguma forma caracterizar aspectos próprios do seu contexto cultural. Foi o caso da escolha do cavalo, do boi e do jegue, escolhidos por estarem diretamente relacionados ao festejo tradicional da região, a vaquejada, que além de proporcionar entretenimento é uma fonte de renda.

Enquanto muitos manifestaram admiração e simpatia para com alguns animais, outros expressaram sentimento oposto, alguns alunos atribuíram características negativas e demonstraram ter aversão por certos animais, especificamente aos que pertencem ao grupo dos insetos. Um meio de contribuir com a desconstrução de uma visão pejorativa sobre determinados grupos, seria a problematização em aula da 
perspectiva antropocêntrica e utilitarista que pauta a relação homem e demais espécies (TRINDADE; SILVA JUNIOR; TEIXEIRA, 2012), realizando uma abordagem que enfatize a importância ambiental, os aspectos ecológicos, e evolutivos dos seres vivos ao invés da tradicional memorização de nomes e grupos.

A proposta de classificar intuitivamente os animais citados na etapa anterior, derivada do modelo intuitivo de classificação conforme abordado por Amorim (1999, apud FERREIRA et al. 2008), permitiu conhecer os diferentes critérios utilizados pelos estudantes na classificação da fauna. As semelhanças morfológica, comportamental e ecológica foram critérios utilizados por muitos grupos para classificar os animais, por exemplo:

Grupo D: Eles são da mesma família e são bastante parecidos. É a questão de ter pelos, a aparência e também você vê que o formato...

Grupo H: Nos separamos de acordo com o habitat e algumas coisas que eles tem em comum, aparência, tamanho, cor...

A utilidade e o fato de trazer algum benefício ao homem também foi um dos critérios utilizados nas classificações, a exemplo do agrupamento realizado pelo Grupo $\mathrm{B}$, que criou a categoria "animais de produção" e do grupo $\mathrm{H}$, destacando a fala:

Grupo: (carneiro, cabra, boi, cavalo, jegue, porco) animais que são criados em fazenda e servem como fonte de renda.

Durante o diálogo de saberes os estudantes notaram as semelhanças entre a classificação feita com base no conhecimento cientifico e as classificações intuitivas. Esse momento foi oportuno para comentar que nos dois casos foram usados critérios diferentes para agrupar os animais. Conforme Baptista (2010), as diferentes visões de natureza que os estudantes possuem podem ou não ser compatíveis com a visão científica, assim o diálogo entre essas visões não visa a hierarquização do conhecimento, mas sim uma oportunidade para que ideias distintas sejam expostas e consideradas respeitando o alcance e aplicação de cada uma. Ainda segundo Baptista (2010, p. 687), no ensino de ciências, [...] "deve haver oportunidades para que os estudantes delimitem, isto é, reconheçam os domínios particulares do discurso em que as suas concepções e as ideias científicas tenham - cada qual no seu contexto - alcance e validade". Assim, a delimitação de saberes permite ao aluno identificar e escolher quando necessário qual concepção adotar em diferentes situações do seu cotidiano.

\section{CONSIDERAÇÕES FINAIS}

O modo como os diversos grupos culturais relacionam-se com a fauna é de certa forma um reflexo dos sentidos e valores atribuídos a cada grupo animal especifico. É perceptível que para os estudantes participantes dessa pesquisa, alguns grupos possuem grande valor afetivo, econômico e cultural, enquanto que a outros é atribuído valor negativo e pejorativo. A partir dessa proposta foi possível conhecer diferentes categorias diretamente associadas à percepção dos estudantes sobre a fauna, muitas das quais não apresentam valor taxonômico, mas são significativas por expressarem o valor simbólico e cultural que os estudantes da EFA apresentam sobre animais que pertencem ou não ao seu ambiente e convívio. Sobre o conhecimento apresentado pelos estudantes, além de ser justificado pelo histórico ensino ministrado nas escolas, é notório que este tem forte relação com o contexto em que eles se inserem. Os estudos e abordagens de cunho etnobiológicos permitem entender como se dá a construção das relações estabelecidas 
com animais considerando os aspectos culturais de cada grupo social, podendo contribuir para que as sociedades mantenham relações com a natureza que visem a preservação de seus constituintes, bem como a preservação dos saberes produzidos e aprendidos a partir da relação direta que o ser humano mantém com o meio que o circunda. A abordagem utilizada na presente pesquisa mostra grande potencial enquanto estratégia que permite a criação de um espaço em que os estudantes possam interagir e participar, promovendo o diálogo entre professor/aluno/conteúdo.

\section{REFERÊNCIAS}

BAPTISTA, G. C. S. Importância da demarcação de saberes no ensino de ciências para sociedades tradicionais. Ciência \& Educação, v. 16, n. 3, p. 679-694, 2010. Disponível em: http://www.scielo.br/pdf/ciedu/v16n3/v16n3a12.pdf Acesso em: 11. jun. 2018.

BARDIN, L. Análise de conteúdo. São Paulo: Edições 70, 2004, 229 p.

DESCOLA, Philippe. Estrutura ou sentimento: a relação com o animal na Amazônia. Mana, v.4, n.1, p.23-45, 1998. Disponível em:

http://www.scielo.br/pdf/mana/v4n1/2425.pdf Acesso em: 17. jul. 2018.

DIEGUES, A. C. S. Etnoconservação: novos rumos para a conservação da natureza. São Paulo: Hucitec-NUPAUB-USP, 2000. 289 p.

EFA VALENTE. Projeto Político Pedagógico. Valente: APAEFA, 2015.

POSEY, D. A. Etnobiologia: teoria e prática. In: RIBEIRO, D. (Ed.). Suma etnológica brasileira. 1. ed. Petrópolis: Vozes, 1987. v. 1. p. 1-15.

TRINDADE, O. S. N; SILVA JÚNIOR, J. C; TEIXEIRA, P. M. M. Um estudo das representações sociais de estudantes do ensino médio sobre os insetos. Revista Ensaio, v.14, n. 03, p. 37-50, 2012. Disponível em:

http://www.scielo.br/pdf/epec/v14n3/1983-2117-epec-14-03-00037.pdf Acesso em: 11. jun. 2018.

TRIPP, D. Pesquisa-ação: uma introdução metodológica. Educação e Pesquisa, v. 31, n. 3, p. 443-466, 2005. Disponível em

http://www.scielo.br/pdf/\%0D/ep/v31n3/a09v31n3.pdf Acesso em 16. jul. 2018. 